\title{
UMA RELAÇÃO ENTRE DÊIXIS E METADISCURSIVIDADE
}

\section{A RELATION BETWEEN DEIXIS AND METADISCOURSE}

\author{
Mônica Magalhães Cavalcante ${ }^{1}$ \\ Mayara Arruda Martins ${ }^{2}$
}

\section{RESUMO}

Neste trabalho, com o objetivo de examinar a relação entre a dêixis e as estratégias metadiscursivas de posicionamento e de engajamento que desempenha nos textos, pretendemos analisar os efeitos de sentido criados a partir da relação dêixis-metadiscursividade, considerando, principalmente, a condição enunciativa própria da dêixis. Quanto à dêixis, valemo-nos de autores como Bühler (1982[1934]), Benveniste (1988[1976]), Cavalcante (2000) e Ciulla (2002, 2008). Para esses autores, os dêiticos constituiriam elementos que indicariam o ponto de origem do locutor, a origo da situação enunciativa, a partir do qual a interação se dá. Sobre o metadiscurso, valemo-nos principalmente de Hyland (2005a, 2005b), em que temos a divisão entre o metadiscurso textual e o interacional, quer as marcas se refiram a porções mais cotextuais, quer se refiram a relações entre os interlocutores. Além disso, o autor apresenta diversos subníveis de posicionamento e de engajamento. Neste artigo, por um recorte metodológico, nos deteremos especificamente às marcas de automenção e aos pronomes de referência ao leitor, subtipos de posicionamento e engajamento, respectivamente, visto que se constituem a partir de marcas essencialmente dêiticas, como pronomes pessoais e pronomes possessivos. Demonstraremos tais marcas em piadas disponíveis no site "piadasnet.com". Não escolhemos o texto por um critério temático ou de gênero, mas pelas ocorrências das formas dêiticas. Não atentamos para a quantidade de ocorrências ou casos, mas sim, aos efeitos de sentido que a relação dêixis-metadiscursividade pode exercer no texto para análise. Estamos pressupondo que o uso de formas dêiticas pode constituir diferentes marcas de metadiscursividade e, por essa razão, colabora para o direcionamento argumentativo que o locutor pretende dar ao texto, uma vez que as marcas de automenção e os pronomes de referência ao leitor são

\footnotetext{
${ }^{1}$ Doutora em Linguística pela Universidade Federal de Pernambuco (UFPE). Professora do Departamento de Letras Vernáculas e do Programa de Pós-Graduação em Linguística da Universidade Federal do Ceará (UFC). Bolsista de Produtividade em Pesquisa nível PQ-1 do Conselho Nacional de Desenvolvimento Científico e Tecnológico (CNPq). Orcid: https://orcid. org/0000-0002-5561-3993.

2 Mestra em Linguística pela Universidade Federal do Ceará (UFC). Doutoranda do Programa de Pós-Graduação em Linguística da Universidade Federal do Ceará (UFC). Bolsista do Conselho Nacional de Desenvolvimento Científico e Tecnológico (CNPq). Orcid: https://orcid.org/0000-0001-5673-0780.
} 
formados essencialmente por dêiticos pessoais e que, ao mesmo tempo, o uso desses dêiticos evidencia um caráter metadiscursivo na interação entre os interlocutores, que tanto se marcam quanto evocam seus interlocutores nas situações enunciativas. Cremos ainda que os tipos de dêixis podem ser utilizados como estratégias metadiscursivas e que, nesses usos, essas formas dêiticas colaboram para reforçar posicionamentos e para tentar influenciar o outro.

Palavras-chave: Dêixis. Metadiscursividade. Efeitos de sentido.

\section{ABSTRACT}

In this paper, in order to examine the relations between deixis and metadiscoursive strategies of stance and engagement these forms play within the texts, we intend to analyze the effects of meaning created from the relation deixis-metadiscourse, by mainly considering the enunciative condition unique to deixis. With respect to deixis, we draw on author such as Bühler (1982 [1934]), Benveniste (1988 [1976]), Cavalcante (2000) e Ciulla (2002, 2008). For these authors, deictics would constitute elements that would indicate the origin point of the speaker, the origo of the enunciative situation, from which the interaction happens. With respect to metadiscourse, we mainly draw on Hyland (2005a, 2005b), in which we find the division between textual and interactional metadiscourse, with the marks referring either to more cotextual portions, or to relations between interlocutors. Moreover, the author presents various sublevels of stance and engagement. In this paper, following a methodological approach, we will specifically focus on marks of self mention and reader pronouns, which are subtypes of positioning and commitment, respectively, since they arise from essentially deictic marks, such as personal and possessive pronouns. We will show these marks in jokes available at "piadasnet.com". We did not choose the text because of its theme or genre, but because of the instances of deictic forms. We did not pay attention to the quantity of occurrences or its cases, but only to the effects of meaning the deixis-metadiscourse relation might exert upon the text under analyse. We assume the use of deictic forms might constitute different marks of metadiscourse and, for that reason, collaborates for the argumentative directing the speaker intends to give the text, since the marks of self mention and the reader pronouns are essentially formed by person deictics and that, at the same time, the use of these deictics shows a metadiscoursive aspect within the interaction between interlocutors, which both highlight and evoke its interlocutors inside enunciative situations. We also believe the types of deixis might be used as metadiscursive strategies and that, within these uses, these deictic forms cooperate to reinforce stances and to try to influence the other.

Keywords: Deixis. Metadiscourse. Effects of meaning.

\section{INTRODUÇÃO}

A motivação para este trabalho surgiu do interesse em diferentes efeitos de sentido que o uso de dêiticos pode trazer a textos de gêneros diversos. Com o objetivo de examinar as relações entre as diferentes formas de tipos dêiticos e as estratégias metadiscursivas de posicionamento e de engajamento que estas desempenham nos textos, pretendemos atentar para os efeitos de sentido criados a partir da relação dêixis-metadiscursividade, uma vez que a maioria dos estudos na área tem dedicado atenção a cada uma dessas abordagens separadamente. Além disso, tendo em vista o grande interesse pelos efeitos de sentido que podem ser criados a partir da utilização de marcas 
dêiticas e considerando, principalmente, a condição enunciativa própria da dêixis, acreditamos ser necessário um estudo que analise o comportamento dos dêiticos em textos de gêneros diversos.

Cremos que os tipos de dêixis podem ser utilizados como estratégias metadiscursivas e que, nesses usos, essas formas dêiticas colaboram para reforçar posicionamentos e para tentar influenciar o outro.

A dêixis, processo referencial de análise neste trabalho, caracteriza-se por sua função ostensiva e subjetiva definida por Bühler (1982[1934]) a partir de coordenadas estabelecidas pelo eu-aqui-agora. Posteriormente, autores como Benveniste (1988[1976]) e Lahud (1979) salientaram na dêixis os traços de subjetividade inseridos na situação comunicativa. É neste caráter intersubjetivo característico da dêixis que acreditamos consistir efeitos metadiscursivos entre os interlocutores.

Sobre o metadiscurso, valemo-nos principalmente de Hyland (2005b), em que temos a divisão entre o metadiscurso textual e o interacional, quer as marcas estejam relacionadas a porções mais cotextuais, quer estejam relacionadas a relações entre os interlocutores. Embora acreditemos que os traços do metadiscurso textual possam ser formados por processos referenciais, acreditamos que são as marcas do metadiscurso interacional que podem ser formadas, em maior quantidade, pelo uso de dêiticos.

Hyland (2005a) apresenta elementos que evidenciam posicionamento e engajamento. Os elementos do posicionamento são os atenuadores, os intensificadores/reforçadores, os marcadores de atitude e as automenções. Os atenuadores indicam a decisão do autor de mostrar o compromisso com a proposição; os reforçadores indicam como os autores expressam suas certezas naquilo que dizem; os marcadores de atitude têm caráter mais afetivo, expressando surpresa, frustração etc.; e as automenções apresentam informações interpessoais à medida que os autores se posicionam em relação aos seus argumentos e seus leitores.

Os elementos do engajamento são os pronomes de referência ao leitor, os apartes pessoais, as diretivas, as questões e o apelo ao conhecimento compartilhado. Com os pronomes de referência ao leitor, o autor introduz o leitor no discurso; com os apartes pessoais, é possível que o escritor se dirija ao leitor diretamente, através de um comentário; com as diretivas, o autor instrui o leitor a desempenhar uma ação que julga importante; com as questões, o autor atrai o leitor; com o apelo ao conhecimento compartilhado, o autor busca encontrar um ponto comum entre o que ele e o leitor pensam.

No entanto, neste artigo, nos deteremos especificamente às marcas de automenção e aos pronomes de referência ao leitor, subtipos de posicionamento e engajamento, respectivamente, visto que se constituem a partir de marcas essencialmente dêiticas, como pronomes pessoais e pronomes possessivos.

\section{A DÊIXIS}

A dêixis foi caracterizada inicialmente, por Bühler (1982[1934]) a partir de coordenadas estabelecidas pelo eu-aqui-agora. Posteriormente, autores como Benveniste (1988[1976]) e Lahud (1979) enfatizaram a subjetividade presente nela. Os dêiticos constituiriam elementos que apontariam para o ponto de origem do locutor. A situação enunciativa, para esses autores, depende do que está relacionado diretamente ao locutor. Bühler (1982[1934]) o concebe como a origo, o ponto zero da comunicação, a partir do qual a interação se dá. É por esse mesmo motivo que outros autores, tais como Lyons (1977) e Cervoni (1989) consideram que o locutor é o referencial da 
atividade enunciativa, sendo esta egocêntrica, uma vez que "exige" a marcação do ponto de vista a partir do qual serão apontados também o espaço e o tempo que a ele estão relacionados.

O fenômeno da dêixis envolve aspectos da própria situação comunicativa, o que, no entanto, não impede que se tenha relação com aspectos também cotextuais, visto que os dêiticos podem figurar tanto como introdução referencial quanto como anáfora, como bem mostram Cavalcante (2000) e Ciulla (2002).

Considerando o locutor como ponto de referência, vale frisar que Benveniste (1988) estabelece que, para cada "eu" da enunciação, há um "tu" pressuposto e que ambos se opõem a "ele", à "não pessoa", ao "referente" sobre o qual se fala.

A literatura sobre o assunto costuma subdividir a dêixis em seis tipos: pessoal, social, espacial, temporal, textual e memorial.

Segundo os níveis de grau de pessoalidade propostos por Cavalcante (2000), a dêixis pessoal é a que apresenta maior grau de pessoalidade, sendo, inclusive, a responsável pelas indicações dos demais tipos de dêixis. É neste tipo de dêixis que nos deteremos neste trabalho. As formas mais tradicionais de dêixis pessoais são aquelas que marcam a primeira e a segunda pessoa, como os pronomes pessoais, os pronomes possessivos, assim como as demais marcas que se refiram aos participantes da situação de enunciação.

Em Ciulla (2008), encontramos elencadas diversas funções que os processos referenciais, inclusive a dêixis, podem trazer aos textos, como a explicitação de pontos de vista e o caráter metadiscursivo. A autora chegou a algumas contribuições que a função metadiscursiva gera nos textos, como organização textual, desenvolvimento argumentativo e orientação ao interlocutor. Foi principalmente essa orientação ao interlocutor atribuída à função metadiscursiva que nos instigou a desenvolver este trabalho, com o apoio de trabalhos de autores como Hyland (2005a). A autora demonstrou, ainda, que várias funções discursivas podem ser desempenhadas simultaneamente pelos processos referenciais, mas nosso foco aqui será especificamente com a relação entre dêixis pessoal e alguns subníveis de engajamento e posicionamento, a saber, automenção e pronomes de referência ao leitor.

\section{A METADISCURSIVIDADE}

É em Hyland (2005a) que encontramos a divisão dos elementos que evidenciam posicionamento e engajamento. Os elementos do posicionamento são os atenuadores, os intensificadores/reforçadores, os marcadores de atitude e as automenções. Os atenuadores indicam a decisão do autor de mostrar o compromisso com a proposição; os reforçadores indicam como os autores expressam suas certezas naquilo que dizem; os marcadores de atitude têm caráter mais afetivo, expressando surpresa, frustração etc.; e as automenções apresentam informações interpessoais à medida que os autores se posicionam em relação aos seus argumentos e seus leitores.

Os elementos do engajamento são os pronomes de referência ao leitor, os apartes pessoais, as diretivas, as questões e o apelo ao conhecimento compartilhado. Com os pronomes de referência ao leitor, o autor introduz o leitor no discurso - é este elemento que ganhará ênfase neste trabalho; com os apartes pessoais, é possível que o escritor se dirija ao leitor diretamente, através de um comentário; com as diretivas, o autor instrui o leitor a desempenhar uma ação que julga importante; com as questões, o autor atrai o leitor; com o apelo ao conhecimento compartilhado, o autor busca encontrar um ponto comum entre o que ele e o leitor pensam. 
Destacamos alguns trabalhos que consideramos relevantes no que diz respeito a determinadas funções discursivas, como Cavalcante e Faria (2009), no que se refere à função metadiscursiva, especificamente.

Nesse trabalho, as autoras atentaram para o emprego dos operadores metadiscursivos na construção argumentativa do texto. Desse trabalho, utilizaremos, sobretudo, as noções de estratégias metadiscursivas que foram aplicadas a diversos processos referenciais, dentre os quais focalizaremos os dêiticos, visto que as autoras não tinham como objetivo verificar somente os subníveis do metadiscurso que se constituem de marcas dêiticas.

Visando à função metadiscursiva, já amplamente explorada em alguns trabalhos, pretendemos demonstrar a que tipos de dêiticos alguns dos subtipos metadiscursivos se relacionam.

\section{METODOLOGIA}

Neste artigo, demonstraremos as marcas de automenção e pronomes de referência ao leitor em piadas disponíveis no site "piadasnet.com". Não escolhemos os textos por um critério temático ou de gênero, mas pelas ocorrências das formas dêiticas. Além disso, não atentamos para a quantidade de ocorrências ou casos, mas sim, à relação dêixis-metadiscursividade presente nos textos.

Portanto, este trabalho busca colaborar, sobretudo, com os estudos da dêixis, tendo como foco a relação entre a intersubjetividade e categorias metadiscursivas de automenção e pronomes de referência ao leitor. A escolha de textos desse gênero se deve ao caráter narrativo dos textos que manifestam muitas piadas. Estamos pressupondo que as narrativas das piadas são uma situação propícia ao aparecimento de dêiticos.

Para analisar o caráter avaliativo do uso das formas dêiticas na piada que apresentamos como exemplo, tomaremos como base a metadiscursividade, proposta por Hyland (2005a), que apresenta marcas características de posicionamento - isto é, formas a partir das quais o autor de um texto deixa evidente "sua voz" - e de engajamento, ou seja, formas que o autor de um texto explicita a fim de direcionar e evocar seus leitores.

\section{RESULTADOS E DISCUSSÕES}

Consideramos que os marcadores metadiscursivos permitem que o locutor se dirija ao interlocutor a fim de atingir diversos objetivos, seja para chamar a sua atenção, orientá-lo na condução dos pontos de vista envolvidos, influenciá-lo ou torná-lo participante direto da atividade comunicativa. Em suma, o locutor utiliza-os a fim de guiar a percepção de um texto pelo interlocutor, deixando evidente a orientação argumentativa adotada. Sabemos que, neste trabalho, não será possível demonstrar todos esses efeitos de sentido causados pela relação dêixis-metadiscursividade, mas pretendemos demonstrar brevemente alguns deles.

Acreditamos, portanto, que os pontos de vista dos interlocutores estão diretamente ligados à dêixis pela característica enunciativa. Para além do próprio enunciado, o fato de ela apontar para traços da própria enunciação explicita o caráter interativo entre locutor e interlocutor. Estamos pressupondo que o uso de formas dêiticas pode constituir diferentes marcas de metadiscursividade e, por essa razão, colabora para o direcionamento argumentativo que o locutor pretende dar ao texto.

Para iniciar a demonstração sobre os dêiticos pessoais que evidenciam o posicionamento e o engajamento dos interlocutores pela referência à primeira pessoa ("eu") e à segunda pessoa ("tu"), observemos o exemplo a seguir: 
(1)

O bêbado entrou na contramão e o guarda o deteve:

- Onde é que o senhor pensa que vai?

- Bom... eu ia pruma festa, mas parece que ela já acabou... Tá todo mundo voltando.

Fonte: https://www.piadasnet.com/piada168bebados.htm Acesso em 15/11/2019.

Nesse primeiro exemplo, é possível perceber uma automenção por meio do uso de "eu" na segunda fala, proferida pelo bêbado. Esse subnível de automenção se apresenta a partir da utilização de um dêitico pessoal e demonstra, desse modo, aquele que fala e se posiciona. Já na fala do guarda, a primeira da piada analisada, percebe-se a utilização de formas dêiticas que instauram o "tu" da situação comunicativa, como "o senhor" associada às formas verbais "pensa" e "vai". Essa instauração do outro se dá, assim, por uma forma de dêixis social ("o senhor"), que, além de interpelar o outro, demonstra uma relação respeitosa no modo de se dirigir ao outro. Desse modo, além de instaurar uma segunda pessoa, a interpelação demonstra uma tentativa de engajar o interlocutor na situação, chamando a atenção dele nesse momento da situação comunicativa simulada.

Observemos mais um exemplo, disponível a seguir:

(2)

Dois bêbados estavam em cima de um prédio e um falou para o outro:

- Cê duvida que eu pule daqui de cima, faça um oito no ar e pouse? hic...

- Duvido! hic... cê vai é se estabacar!!!

Aí o bêbado 1 pulou, fez um oito no ar e pousou, e o bêbado 2 falou:

- Se ele consegue ...hic... eu também consigo!!! hic...

E ele pulou:

- Aaaaaaaahhhhhhhhhhhhh...

Se estabacou, e o um porteiro de um prédio falou:

- Pô aí, o superman quando tá bêbado só faz merda!

Fonte: https://www.piadasnet.com/piada178bebados.htm. Acesso em 25/11/2019.

Do mesmo modo, no exemplo 2, verificamos automenções (“eu”) e pronomes de referência ao interlocutor ("cê") nas falas dos dois bêbados representados na piada. Essas formas dêiticas servem, mais uma vez, para marcar o posicionamento de quem fala e para engajar a pessoa com quem se fala. $\mathrm{O}$ engajamento nessa situação já começa a partir do momento em que o primeiro bêbado instiga o segundo a duvidar (ou não) do desafio proposto por ele, buscando, assim, influenciar o outro com a ação que executará posteriormente. Ambos interagem interdiscursivamente, trocando os papéis de eu e tu, e acabando por realizarem a ação sugerida na primeira fala da piada.

Os subníveis de posicionamento e de engajamento podem servir também para demonstrar os pontos de vista defendidos pelos interlocutores, como podemos verificar no seguinte exemplo:

(3)

- Por que você bebe?

- Eu bebo porque sou egoísta. Gosto que o mundo gire em torno de mim!

- Eu bebo porque sou exigente. E, quando estou bêbado, só vejo mulheres (homens) maravilhosas!

- Eu bebo porque sou solidário. Me preocupo muito com o sustento dos milhões de funcionários das empresas de bebidas alcoólicas e de suas pobres famílias, em vez de ser egoísta e me preocupar com meu fígado.

- Eu bebo pra esquecer, só não me pergunte o quê, porque eu já esqueci! Viu como funciona? 
- Eu bebo pra me distrair. Minha mulher me traiu e eu bebo pra me 'des-trair'! Sai, chifre! Sai, chifre!

- Eu bebo porque sou higiênico. Ouvi falar que a nossa água está cada vez mais infectada com coliformes fecais, poliformes fatais, uniformes de carnavais...ah, sei lá! Seja como for, eu prefiro o álcool!

- Eu bebo porque adoro futebol. E pra aguentar o meu time, só bebendo mesmo!

- Eu bebo porque sou casado. Precisa explicar?

- Eu bebo por recomendação médica. Ele disse pra eu não judiar do meu estômago. E o coitadinho fica tão triste quando eu não bebo. Só vendo...

Fonte: https://www.piadasnet.com/piada150bebados.htm. Acesso em 05/11/2019.

No exemplo para análise, encontramos diversas marcas dêiticas, dentre as quais focalizaremos aquelas que se caracterizam por serem automenções e pronomes de referência ao leitor, subníveis de posicionamento e engajamento, respectivamente. Destacamos, no exemplo, algumas dessas marcas, mas enfatizamos que os dêiticos pessoais são expressos por vários elementos linguísticos que indicam os participantes do ato de comunicação. Desse modo, os pronomes oblíquos ("me"), os pronomes possessivos ("minha"), bem como as formas verbais que se referem às primeiras pessoas também são tipos de dêiticos pessoais.

Destacamos o pronome de primeira pessoa "eu" por ser a forma dêitica pessoal mais clássica, a partir da qual se dão todos os outros tipos dêiticos. No exemplo em análise, percebemos o caráter subjetivo da dêixis a cada atualização na situação enunciativa. A forma se mantém, mas os sujeitos da enunciação se alteram. No entanto, no texto em questão percebemos que os pontos de vista defendidos pelos locutores convergem para a mesma ideia, a de que "beber é bom", o que demonstra que, no exemplo, os argumentos apresentados pelos locutores demonstram uma orientação argumentativa que reforça o ponto de vista em defesa de um grupo, o dos bêbados e reforça a ideia desse estereótipo.

As falas se valem de marcas de automenções, que enfatizam a responsabilidade de quem explica o porquê de beber e dão "autoridade" a quem o diz - e é exatamente isso que gera o humor, a união dos motivos expressos às marcas subjetivas demonstram que quem justifica o fato de beber são os bêbados da situação representada na piada.

Assim como as marcações de primeira pessoa, as de segunda pessoa também são dêiticos pessoais que se classificam como pronomes de referência ao leitor, visto que têm por objetivo convocar o outro para o seu dizer. Logo na pergunta inicial da piada "Por que você bebe?", temos uma marcação intersubjetiva clássica - você - característica dos textos em que há interações diretas entre um locutor e um interlocutor.

Mais adiante, no texto, duas formas verbais - "pergunte" e "viu" - demonstram a intenção do locutor a trazer o interlocutor para o que ele está dizendo, seja para chamá-lo a atenção ou levá-lo a compactuar de suas ideias, aderir ao seu ponto de vista.

Com isso, estamos pressupondo que o uso de formas dêiticas pode constituir diferentes efeitos de sentido que indicam certo direcionamento argumentativo ao texto, principalmente quando relacionadas a subníveis de posicionamento e engajamento hylandianos.

\section{CONSIDERAÇÕES FINAIS}

Conforme dissemos na introdução deste trabalho, foi feito um recorte a partir da ênfase aos efeitos de sentido que os processos referenciais, especialmente os dêiticos, podem exercer em contextos de uso, considerando as funções que já foram apontadas nos trabalhos da literatura especializada. 
Acreditamos, portanto, que os pontos de vista dos interlocutores estão diretamente ligados à dêixis pela característica enunciativa. Para além do próprio enunciado, o fato de ela apontar para traços da própria enunciação explicita o caráter interativo entre locutor e interlocutor.

Consideramos como principal objetivo deste trabalho a relação entre a dêixis e a metadiscursividade, enfatizando que as marcas de automenção e os pronomes de referência ao leitor são formadas essencialmente por dêiticos pessoais, por se relacionarem às pessoas envolvidas na interação. Ao mesmo tempo que possibilitam aos interlocutores tanto se marcar quanto evocar o outro nas situações comunicativas, o uso desses dêiticos pessoais evidencia um caráter metadiscursivo na interação entre os interlocutores, marcando, assim, o posicionamento e o engajamento hylandianos.

Para trabalhos futuros, sugerimos que a investigação da relação entre a dêixis e o metadiscurso seja mais aprofundada e detalhada, explorando, dessa forma, os demais tipos de dêixis e os outros subníveis de posicionamento e engajamento do metadiscurso, visto que, neste trabalho, o foco de análise foram apenas os subníveis de automenção e pronomes de referência ao leitor e os dêiticos pessoais.

\section{REFERÊNCIAS}

BENVENISTE, É. Problemas de linguística geral. 2. ed. Tradução de Maria G. Novak; Maria L. Neri; revisão do Prof. Isaac Nicolau Salum. Campinas: Pontes. 2v. Título original: Problèmes de linguistique générale, 1988.

BÜHLER, K. The deictic field of language and deictic words. In: JARVELLA, R.J.; KLEIN, W. (eds.) Speech, place and action: studies in deixis and related topics. New York: John Wiley and Sons, 1982. p. 9-30.

CAVALCANTE, M. M. Expressões indiciais em contextos de uso: por uma caracterização dos dêiticos discursivos. Recife, 205p. Tese /Doutorado em Lingüística/ - Universidade Federal de Pernambuco (UFPE), 2000.

CAVALCANTE, M. M.; FARIA, M. G. S. Posicionamento e engajamento em redações dissertativas. Disponível em: https://revistas.ufrj.br/index.php/diadorim/article/view/3893. Acesso em: 14 nov 2019.

CERVONI, J. A enunciação. Tradução de L. Garcia dos Santos; revisão do Prof. Valter Kehdi. São Paulo: Ática. Título original: L'énonciation. 1989.

CIULLA, A. A referenciação anafórica e dêitica - com atenção especial para os dêiticos discursivos. Dissertação, 90 p. Mestrado em Linguística. Fortaleza: Universidade Federal do Ceará, 2002.

CIULLA, A. Os processos de referência e suas funções discursivas: o universo literário dos contos. Tese. 201p. Doutorado em Linguística. Fortaleza: Universidade Federal do Ceará, 2008.

HYLAND, K. Metadiscourse: Exploring Interaction in Writing. Continuum: London and New York, 2005a.

HYLAND, K. Stance and engagement: a model of interaction in academic discourse. In: Discourse Studies. v. 7, n. 2. p. 173-192, 2005b.

LAHUD, M. A propósito da noção de dêixis. 1979. São Paulo: Ática.

LYONS, J. Semantics. Cambridge: Cambridge University Press, 1977. 